\title{
Results of the introduction of ornamental peach cultivars from China and Japan
}

\author{
Larisa Komar-Tyomnaya* \\ Nikita Botanical Gardens - National Scientific Center of the RAS, 298648, Yalta, Russian Federation
}

\begin{abstract}
The article presents the results of a nine-year study of 19 ornamental peach cultivars of Chinese and Japanese origin, introduced to the southern coast of Crimea. Cultivars with high ornamentality, degree and duration of flowering were identified. They are accession into earlymedium, medium, mid-late, late and very late flowering groups. Their susceptibility to fungal diseases was determined.
\end{abstract}

\section{Introduction}

Ornamental peaches are spectacular flowering trees. The largest and most diverse gene pool of them is found in Chine, in the homeland of the peach, and in other countries of Southeast Asia [1, 2, 3]. A large collection of these plants is concentrated in the Beijing Botanical Garden. For the Ornamental Peach Festival, which has been held since 1989, 61 cultivars were harvested here from all over the world and 5000 peach trees were planted [2]. Such a collection is of great interest to introductors and breeders.

As part of the agreement on the scientific exchange of varieties, we introduced some cultivars of ornamental peach from the Beijing Botanical Garden. Previously, we presented the morphological characteristics of these varieties, as well as data on the dates of flowering and susceptibility to diseases, obtained over 5 years of observations in the Nikita Botanical Gardens [4]. However, in conditions of unstable meteorological indicators, a longer data collection is required for an objective assessment. The purpose of this study was to summarize the results of a long-term study of the main biological characteristics of new cultivars, to assess the degree of their adaptation to growing conditions on the southern coast of Crimea.

\section{Materials and methods}

Cultivar testing was during 9 years (2012-2020), according to standard procedures [5]. Flowering energy was counted visually using following scores: 0 - no bloom; 1 - less than $10 \%$ of the crown is covered with flowers; $2-25 \%$ of the crown is covered with flowers; 3 - $50 \%$ of the crown is covered with flowers; 4 - $75 \%$ of the crown is covered with flowers; $5-100 \%$ of the crown is covered with flowers. Total ornamentality was determined on a 5point scale, where 5 is the maximum point.

\footnotetext{
*Corresponding author: larissakt@ mail.ru
} 
Morphological characteristics of the plants and blossom periods were evaluated by the testing method for peach varieties for distinctness, uniformity and stability as described by UPOV [6]. Additional characteristics important for ornamental varieties (shape and diameter of the flowers, the number and color of the petals and others) were also evaluated [7].

In an orchard the damage by fungal disease was investigated in condition of plant protection. The evaluation of plant damage by blossom blight and leaf curl was done visually based on the percentage damaged flowers, shoots and leaves, respectively. The level of damaged leaves and shoots by powdery mildew was counted visually based on the following scale: 0 - damage is absent; 1 - there are single infected zones on the leaves not larger then $2 \mathrm{~mm}$ with weakly developed mycelium; 2 - infected zones on the leaves larger then $2 \mathrm{~mm}$ with a moderate development of mycelium and sporulation; 3 -infected zones on the leaves cover up to $50 \%$ of the surface, the development of mycelium and sporulation are strong, there are some spots of mycelium on shoots; 4 - development of mycelium and sporulation are strong, some leaves are drying and drop early.

The collection plantings are located in the western southern-coast subtropical area of the southern macroslope of the Crimean Mountains. This district has the Mediterranean droughty climate with a very mild winter. An average annual rainfalls is $592 \mathrm{~mm}$, an average annual air temperature is $+12.5^{\circ} \mathrm{C}$. An average air temperature of the hottest month (July) reaches $+23.4^{\circ} \mathrm{C}$. An average air temperature of the coldest month (February) is $+3.2^{0} \mathrm{C}$. Absolute minimum of the air temperature descend to $-15.0^{\circ} \mathrm{C}$. Absolute maximum of the air temperature is $+39.0^{\circ} \mathrm{C}$. The period without frosts extends to 254 days. The vegetation period when average air temperature is above $10.0^{\circ} \mathrm{C}$ continues 207 days. The period of intensive plant vegetation (when average air temperature is above $15.0^{\circ} \mathrm{C}$ ) is 148 days.

\section{Results and discussion}

The morphological characteristics of the crown and flower of the new introduced peach cultivars were considered by us earlier [4]. Note here that flower characteristics such as corolla diameter and number of petals may vary slightly from year to year. In general, they depend on the total condition of the tree, the degree of germination of generative buds, the degree of flowering, the development of infections, in regions with colder winters (such as in the steppe Crimea) - from frost. A low degree of flowering eventually contributes to an increase in the diameter of the flowers. The variability of petals number in most cases is determined by the reaction of cultivars to the meteorological factors of the late summer period, when the formation of flower organs in the bud takes place [8,9]. The meteorological conditions of the year play an important role for the quantitative indicators of the flower. But they have a greater influence on the biological characteristics of flowering.

According to the average nine-year data, the flowering of the studied introduced cultivars began in the period from 1 to 17 April. The group of cultivars with up-right crown turned out to be the most diverse by the dates of the beginning of flowering. It contains cultivars belonging to 4 groups according to the flowering period. The earliest among them are 'Fenhong Shanbitao' and 'Hanhong Tao' (Table 1). Three cultivars belong to the medium-term group, four - to the late-flowering group. Very late are 'Bi Tao', 'Fei Tao' and 'Sahong Tao', which begin to bloom on average in mid-April or later, and on this basis lag behind other cultivars by 7-14 days or more. Thus, they extend the flowering season of ornamental peaches, because these are the latest cultivars in the NBG collection. They can also serve as sources of the very late flowering trait for breeding. Cultivars with pillar and weeping crown mainly belong to the group of middle flowering period, with the exception 
of 'Wubao Chuizhi' which blooms in the mid-late term. It should be noted that the revealed trend in the flowering time of the studied cultivars coincides with that in the conditions of the Beijing Botanical Garden [2].

Table 1. Characteristics of ornamental peach cultivars flowering.

\begin{tabular}{|c|c|c|c|c|c|}
\hline Cultivars & $\begin{array}{l}\text { Flowering } \\
\text { period }\end{array}$ & \begin{tabular}{|l} 
Start of the \\
flowering \\
period
\end{tabular} & $\begin{array}{l}\text { Flowering } \\
\text { duration }\end{array}$ & $\begin{array}{l}\text { Flowering } \\
\text { energy }\end{array}$ & $\begin{array}{l}\text { Total } \\
\text { ornamen- } \\
\text { tality }\end{array}$ \\
\hline \multicolumn{6}{|l|}{ Up-right } \\
\hline 'Bi Tao' & VL & 15.04 & 17,8 & 2,8 & 4,1 \\
\hline 'Fei Tao' & VL & 15.04 & 18,6 & 4,3 & 4,8 \\
\hline 'Fenhong Shanbitao' & EM & 1.04 & 22,6 & 4,4 & 4,9 \\
\hline 'Hanhong Tao' & EM & 1.04 & 25,8 & 4,2 & 4,4 \\
\hline 'Jiang Tao' & M & 3.04 & 20,9 & 3,7 & 3,9 \\
\hline 'Ju Tao' & $\mathrm{L}$ & 12.04 & 17,8 & 3,8 & 3,6 \\
\hline 'Kyoumaiko' & $\mathrm{L}$ & 13.04 & 15,9 & 2,9 & 3,2 \\
\hline 'Ningxia Zi Ye' & M & 5.04 & 23,3 & 3,9 & 4,5 \\
\hline 'Sahong Tao' & VL & 17.04 & 10,5 & 1,0 & - \\
\hline 'Wanbai Tao' & $\mathrm{L}$ & 11.04 & 18,9 & 4,1 & 4,7 \\
\hline 'Zan Fen' & $\mathrm{L}$ & 11.04 & 17,9 & 4,4 & 4,9 \\
\hline 'Zi Ye Tao' & M & 4.04 & 21,0 & 3,7 & 4,5 \\
\hline \multicolumn{6}{|c|}{ Pillar } \\
\hline 'Terutehime' & M & 2.04 & 18,8 & 4,6 & 4,6 \\
\hline 'Terutebeni' & M & 2.04 & 20,8 & 3,4 & 3,7 \\
\hline 'Teruteshiro' & M & 2.04 & 19,8 & 3,3 & 3,7 \\
\hline \multicolumn{6}{|c|}{ Weeping } \\
\hline 'Hongyu Chuizhi' & M & 5.04 & 16,1 & 3,7 & 3,8 \\
\hline 'Wubao Chuizhi' & ML & 8.04 & 18,4 & 3,8 & 3,9 \\
\hline 'Yuanping Chuizhi' & M & 5.04 & 15,9 & 3,7 & 3,5 \\
\hline 'Yuanyang Chuizhi' & M & 4.04 & 19,5 & 3,5 & 4,0 \\
\hline
\end{tabular}

The flowering of the introduced cultivars lasted on average from 10.5 to 25.8 days. 6 cultivars bloomed for more than 20 days. The longest blooming is 'Hanhong Tao'. It is 
noteworthy that late flowering cultivars were characterized by shorter flowering. This was especially clearly demonstrated by 'Sahong Tao' (10.5 days). This is due to higher temperatures in the second half of April, which reduce the duration of flowering.

Table 2. The incidence of fungal diseases of ornamental peach cultivars.

\begin{tabular}{|c|c|c|c|}
\hline Cultivars & $\begin{array}{l}\text { Blossom } \\
\text { blight, \% }\end{array}$ & $\begin{array}{c}\text { Leaf curl, } \\
\% \\
\end{array}$ & $\begin{array}{c}\text { Powdery } \\
\text { mildew, point }\end{array}$ \\
\hline \multicolumn{4}{|c|}{ Up-right } \\
\hline 'Bi Tao' & 5,9 & 5,4 & 1,9 \\
\hline 'Fei Tao' & 9,1 & 13,3 & 1,9 \\
\hline 'Fenhong Shanbitao' & 11,3 & 12,9 & 2,0 \\
\hline 'Hanhong Tao' & 23,1 & 8,9 & 1,4 \\
\hline 'Jiang Tao' & 8,8 & 21,1 & 2,3 \\
\hline ‘Ju Tao' & 4,1 & 3,6 & 1,8 \\
\hline 'Kyoumaiko' & 1,7 & 8,4 & 1,5 \\
\hline 'Ningxia Zi Ye' & 3,3 & 16,2 & 1,8 \\
\hline 'Sahong Tao' & 1,2 & 14,8 & 1,6 \\
\hline 'Wanbai Tao' & 5,9 & 11,8 & 1,4 \\
\hline 'Zan Fen' & 16,6 & 5,3 & 1,9 \\
\hline 'Zi Ye Tao' & 12,0 & 21,9 & 2,6 \\
\hline \multicolumn{4}{|c|}{ Pillar } \\
\hline 'Terutehime' & 12,8 & 8,8 & 1,8 \\
\hline 'Terutebeni' & 10,5 & 4,5 & 1,8 \\
\hline 'Teruteshiro' & 8,3 & 8,1 & 1,4 \\
\hline \multicolumn{4}{|c|}{ Weeping } \\
\hline 'Hongyu Chuizhi' & 14,7 & 8,6 & 2,0 \\
\hline 'Wubao Chuizhi' & 3,9 & 4,9 & 1,4 \\
\hline 'Yuanping Chuizhi' & 6,0 & 1,9 & 1,6 \\
\hline 'Yuanyang Chuizhi' & 3,0 & 16,0 & 1,0 \\
\hline
\end{tabular}

Flowering energy of the accessions varied from 1 to 4.6 points. The most stable lush flowering above 4 points was noted in the cultivars cultivars 'Fei Tao', 'Fenhong Shanbitao', 'Hanhong Tao', 'Terutehime', 'Wanbai Tao', 'Zan Fen'. The smallest flowering energy of 'Sahong Tao' (1 point) is explained by a strong drop of generative buds before blooming, the cause of which may be an infection. 
The total ornamentality of trees depends on the flowering energy and the quality of the flowers. In the studied cultivars, it was in the range from 3.2 to 4.9 points. 10 cultivars with a rating of 4 points and above were identified. The most ornamental of them are 'Fenhong Shanbitao', 'Zan Fen', 'Fei Tao', 'Wanbai Tao', 'Terutehime'.

All accessions of ornamental peach are affected by the main fungal diseases. Sensitivity to pathogens varies by cultivar and increases in years favorable for their development.

The average long-term damage of flowering shoots of the studied cultivars by blossom blight reached $23.1 \%$. The least susceptible to blossom blight was shown by 'Sahong Tao' and 'Yuanyang Chuizhi', in which the number of affected shoots did not exceed $2 \%$. Damage with leaf curl was 1.9-21.1\%. 'Yuanping Chuizhi' and 'Ju Tao' demonstrated significant tolerance to this pathogen (1.9-3.6\%). A noticeable degree of powdery mildew development was fixed in most cultivars, with the exception of 'Yuanyang Chuizhi' (1 point without sporulation). It should be noted that its distribution within the crown is not so significant in some years, although it is estimated with a high score due to the presence of sporulation.

The studied cultivars were not exposed to low negative temperatures in the conditions of mild winters on the South Coast of the Crimea. The results of modeling frost resistance of introduced plants for colder regions will be reported additionally.

\section{Conclusions}

The introduced cultivars of ornamental peach of Chinese and Japanese origin are a valuable material for gardening and breeding. They are characterized by high ornamentality, enriching the assortment, and bloom at various terms, expanding the flowering range of the ornamental peach from the NBS collection. Their agricultural equipment should include plant protection measures due to their susceptibility to fungal pathogens. In the conditions of the South Coast of the Crimea, the studied cultivars can be grown without taking into account their frost resistance.

\section{References}

1. W. Yulin, Genetic Resources of deciduous fruit and nut crop in China (China Agricultural Science and Technology Press, Beijing, 2002).

2. D. Hu, Z. Zhang. Ornamental peaches. Zhongguo lin ye chu ban she, Beijing. (2010).

3. M. Yoshida, K. Yamane, Y. Ijiro, N. Fujishige, M. Yamaguchi, E. Takahashi, Studies on ornamental peach cultivars. Bulletin of the College of Agriculture, Utsunomiya University 17, 3 (2000)

4. L. D. Komar-Tyomnaya, Acta Hortic., 1208 (2018).

5. E. N. Sedov, T.P. Ogoltsova (ed.). Program and methods of fruit, berry and nut crops testing (Orel, 1999)

6. UPOV Guidelines for the conduct of test for distinctness, uniformity and stability. Peach, nectarine (Prunus persica (L.) Batsch.) TG 53/6 (1995).

7. L. D. Komar-Tyomnaya, Official bull. of State service on guard of the rights on plants varieties 3(1) (2007)

8. L. D. Komar-Tyomnaya, Proceedings of the Kuban State Agrarian University 4(73) (2018)

9. T. A. Latsko, L. D. Komar-Tyomnaya, Acta Hortic. 1282 (2020). 